\title{
Cortical bone loss is an early feature of nonradiographic axial spondyloarthritis
}

Anna Neumann ${ }^{1+}$, Judith Haschka ${ }^{1,2+}$, Arnd Kleyer ${ }^{1}$, Louis Schuster ${ }^{1}$, Matthias Englbrecht ${ }^{1}$, Andreas Berlin ${ }^{1}$, Camille P. Figueiredo ${ }^{1,3}$, David Simon ${ }^{1}$, Christian Muschitz ${ }^{2}$, Roland Kocijan ${ }^{2}$, Heinrich Resch², Jürgen Rech ${ }^{1}$ and Georg Schett ${ }^{*}$

\begin{abstract}
Background: In the present study, we investigated bone geometry, microstructure, and volumetric bone mineral density (VBMD) in a cohort of patients with nonradiographic axial spondyloarthritis (nr-axSpA) in order to define the early bone changes occurring in axial spondyloarthritis (axSpA) and to define potential factors for deterioration of bone microstructure.

Methods: Patients with axSpA ( $n=107)$ and healthy control subjects $(n=50)$ of similar age and sex were assessed for geometric, volumetric, and microstructural parameters of bone using high-resolution peripheral quantitative computed tomography (HR-pQCT) at the radius. Additionally, demographic and disease-specific characteristics of patients with axSpA were recorded.

Results: Patients with nr-axSpA and control subjects were comparable in age, sex, and body mass index. Geometric and microstructural analysis by HR-pQCT revealed a significantly reduced cortical area $(p=0.022)$ and cortical thickness $(p=0.006)$ in patients with nr-axSpA compared with control subjects. Total and cortical vBMD were significantly reduced in patients with $\mathrm{nr}$-axSpA $(p=0.042$ and $p=0.007$, respectively), whereas there was no difference in trabecular VBMD. Patients with a short disease duration $(<2$ years; $n=46)$ also showed significant reduction of cortical thickness and cortical area compared with control subjects. Patients with disease duration $>2$ years $(n=55)$ additionally developed a decrease of cortical and total VBMD. Multiple regression models identified male sex to be associated with lower cortical VBMD and female sex to be associated with lower trabecular vBMD.
\end{abstract}

Conclusions: Bone microstructure in patients with nr-axSpA is characterized primarily by deterioration of cortical bone. Cortical bone loss starts early and is evident within the first 2 years of the disease.

Keywords: Spondyloarthritis, Bone loss, Computed tomography

\section{Background}

Spondyloarthritis $(\mathrm{SpA})$ comprises a group of diseases with shared genetic and pathophysiologic backgrounds affecting the axial and peripheral skeleton. Axial disease comprises nonradiographic axial SpA (nr-axSpA) and ankylosing spondylitis (AS). Axial inflammation leads to local bone formation with progressive ankylosis of sacroiliac joints as well as syndesmophyte formation. Nonetheless, systemic bone loss

\footnotetext{
* Correspondence: georg.schett@uk-erlangen.de

${ }^{\dagger}$ Anna Neumann and Judith Haschka contributed equally to this work.

${ }^{1}$ Department of Internal Medicine 3, Friedrich Alexander University

Erlangen-Nurnberg and Universitätsklinikum Erlangen, Ulmenweg 18, 91054

Erlangen, Germany

Full list of author information is available at the end of the article
}

and increased vertebral and nonvertebral fracture risk have been described in AS [1].

Authors of a recent review of the literature on bone mass in AS reported a prevalence of osteoporosis varying from $3 \%$ to $47 \%$ according to different measurement techniques and patient selection criteria, whereas osteopenia has been reported in up to $88 \%$ of patients [2] These variations may be based on the fact that bone analysis in nr-axSpA and AS is challenging, particularly in the axial skeleton, where it is confounded by local new bone formation. Especially in patients with syndesmophytes, dual-energy X-ray absorptiometry (DXA) is unreliable because it sums up new bone formation with bone loss owing to its two-dimensional nature $[3,4]$.

(C) The Author(s). 2018 Open Access This article is distributed under the terms of the Creative Commons Attribution 4.0 International License (http://creativecommons.org/licenses/by/4.0/), which permits unrestricted use, distribution, and 
However, bone loss has also been found at the hip of patients with AS [5-8]. Furthermore, quantitative computed tomography (QCT), which separately measures trabecular and cortical volumetric bone density, has supported the occurrence of bone loss in AS, showing reduced trabecular volumetric bone mineral density (vBMD) in the lumbar spine in severe AS with syndesmophyte formation [9].

Systemic inflammation is at least partly responsible for systemic bone loss in patients owing to proinflammatory cytokines leading to a direct activation of osteoclastogenesis [10]. In prior studies, patients with AS showed significant bone loss as measured by DXA at the lumbar spine compared with patients with mechanical back pain [11]. Further, in the DESIR (DEvenir des Spondyloarthrites Indifférenciées Récentes) cohort, $71.4 \%$ of patients with inflammatory back pain fulfilled Assessment of Spondyloarthritis international Society (ASAS) classification criteria for axial spondyloarthritis (axSpA), and in multiple logistic regression analyses, bone marrow edema seen on magnetic resonance imaging scans, markers of inflammation such as C-reactive protein (CRP) and erythrocyte sedimentation rate (ESR), and male sex were associated with lower bone mineral density (BMD) at any site [12]. Inhibition of tumor necrosis factor (TNF)- $\alpha$ has been reported to show a beneficial effect on BMD and bone turnover markers of patients with AS, thereby supporting the role of systemic inflammation on bone metabolism [13-15]. In accordance with this, vertebral fractures in patients with AS are associated with the longer disease duration independent of age [16].

Bone strength depends not only on BMD but also on bone geometry and microarchitectural aspects of cancellous and cortical bone [17, 18]. High-resolution quantitative computed tomography (HR-pQCT) permits a noninvasive, three-dimensional assessment of bone geometry, volumetric BMD, and microarchitecture, which resembles a virtual bone biopsy of peripheral bone $[19,20]$. HR-pQCT data have been shown to correlate with BMD results obtained by DXA and with incident fracture risk in the radius, hip, and spine in postmenopausal women [21, 22].

The aim of the present study was to investigate bone microstructure, geometry, and vBMD using HR-pQCT in a large cohort of patients with nr-axSpA in early stages of disease and to search for potential risk factors for deterioration of bone microstructure. In this context, it is important to mention that patients with AS with long-standing disease are characterized by reduction of total and cortical vBMD and cortical thickness, as well as increased cortical porosity [23, 24]. Data on early disease, however, which may reflect the initial changes of bone in $\mathrm{nr}-\mathrm{axSpA}$, are missing to date.

\section{Methods}

\section{Patients and control subjects}

A total of 107 Caucasian patients with a diagnosis of $n r-a x S p A$ were recruited at the Department of Internal Medicine 3 of the University of Erlangen-Nuremberg, Germany. All patients fulfilled the ASAS classification criteria. Patients with AS were not included in this study because we were specifically seeking to study a population with early bone changes. Recruitment of healthy control subjects has been described elsewhere, and these individuals were matched by age and sex [25]. Briefly, exclusion criteria for being a healthy control subject were (1) presence or history of chronic joint pain/ swelling, (2) presence of systemic diseases, (3) documented osteopenia/osteoporosis, (4) present or past use of bisphosphonates or prednisolone, and (5) positivity for anticitrullinated protein antibodies (ACPA) or rheumatoid factor. This study was approved by the local ethics committee and the national radiation safety agency (Bundesamt fur Strahlenschutz). Informed consent was obtained from each patient, and the study was performed in accordance with the Declaration of Helsinki.

\section{Demographic and disease-specific characteristics}

Demographic characteristics, disease duration, features of SpA (psoriasis, inflammatory bowel disease [IBD], uveitis), human leukocyte antigen (HLA)-B27 status, ESR, and serum CRP levels were recorded in all patients. Current disease activity was determined by Ankylosing Spondylitis Disease Activity Score (ASDAS-CRP; inactive disease ASDAS-CRP $<1.3,1.3-2.0$ moderate disease activity, 2.13.5 high disease activity, $>3.5$ very high disease activity). Spinal mobility was assessed by Bath Ankylosing Spondylitis Metrology Index (BASMI). For the assessment of present enthesitis, the Maastricht Ankylosing Spondylitis Enthesitis Score was used. Peripheral arthritis was assessed by 78 tender and 76 swollen joint counts. The Spondylitis Disease Activity Index (BASDAI) was assessed as a secondary disease activity measure, and the Bath Ankylosing Spondylitis Functional Index (BASFI) was used for patient-reported outcomes.

The use of conventional disease-modifying antirheumatic drugs (methotrexate, sulfasalazine, azathioprine, leflunomide, chloroquine, gold) and biologic agents (TNF inhibitors [TNFi]) was recorded. Further, the current or previous use of systemic glucocorticoid (GC) treatment exceeding continuous treatment with $5 \mathrm{mg}$ of prednisolone-equivalent daily for more than 3 months was assessed. Treatment with nonsteroidal anti-inflammatory drugs was also recorded (on demand, daily). History of nontraumatic fractures, diagnosis of osteoporosis, and previous or ongoing antiresorptive treatment or supplementation of $25(\mathrm{OH})$ vitamin $\mathrm{D}_{3}$ and calcium was taken. 


\section{High-resolution peripheral quantitative computed tomography}

HR-pQCT imaging was performed in all patients and 50 healthy age- and sex-matched control subjects using the XtremeCT scanner (SCANCO Medical, Brüttisellen, Switzerland). The scan region was selected according to the manufacturer's standard in vivo protocol of the ultradistal radius of the dominant hand. For measurement, the patient's hand was immobilized using a carbon fiber shell to reduce movement. Standardization of measurements was ensured by daily cross-calibrations with a standardized control phantom (QRM, Moehrendorf, Germany). The ROI was determined with an anteroposterior scout view and was fixed $9.5 \mathrm{~mm}$ proximal from the reference line. The effective dose for each scan was $<3 \mu \mathrm{Sv}$. The reference line was set manually. The scan ROI was examined in 110 parallel slices $(82-\mu \mathrm{m}$ voxel size) with a total measurement time of 2.8 minutes. All measurements and evaluations were performed using the manufacturer's standard software. Motion grading (1-5) of each scan was performed using SCANCO Medical standard operating procedure scale, and scans graded $>3$ were excluded from analysis.

vBMD, bone microstructure, and geometry were measured with HR-pQCT. Three-dimensional vBMD of the total radius (total $\mathrm{BMD}$ in $\mathrm{mg}$ of hydroxyapatite $[\mathrm{HA}] / \mathrm{cm}^{3}$ ), the cortical shell $\left(\mathrm{Ct} . \mathrm{BMD}, \mathrm{mg} \mathrm{HA} / \mathrm{cm}^{3}\right)$, and the trabecular compartment (Tb.BMD, mg HA/ $\mathrm{cm}^{3}$ ) were extracted. Additional, distinctive results of trabecular BMD adjacent to bone cortex $\left(\mathrm{mg} \mathrm{HA} / \mathrm{cm}^{3}\right)$ and central medullary trabecular BMD $\left(\mathrm{mg} \mathrm{HA} / \mathrm{cm}^{3}\right)$ were expressed. Results of bone microstructure included bone volume fraction $(\mathrm{BV} / \mathrm{TV}, \%)$, trabecular number $\left(\mathrm{mm}^{-1}\right)$, trabecular thickness $(\mu \mathrm{m})$, trabecular separation (Tb.Sp, $\mu \mathrm{m})$, inhomogeneity of the trabecular network $(\mu \mathrm{m})$, cortical thickness (Ct.Th, $\mu \mathrm{m})$, and cortical porosity (Ct.Po, $\%)$. Furthermore, bone geometry was represented by total, cortical, and trabecular bone area $\left(\mathrm{mm}^{2}\right)$. All these parameters were calculated by using automated software. Reliability of the automated contouring method of the Xtreme CT scanner software has recently been shown [26].

\section{Statistical analysis}

Data were collected, organized, and analyzed using IBM SPSS Statistics software (IBM, Armonk, NY, USA). If not stated otherwise, categorical variables are presented as number and percent, and continuous variables are provided as median (IQR). Inferential comparisons comprised chi-square tests for categorical variables (indicated as number and percent in the tables) to check for observed deviations from expected frequencies, as well as the Kruskal-Wallis and Mann-Whitney $U$ tests to compare data derived from interval scales. To investigate potential relationships of total, cortical, and trabecular
vBMD with disease-related or demographic parameters, multiple linear regression models were computed with an enter procedure including all predictors at a single step. The first model incorporated sex, age, BMI, and smoking status. The second model included sex, age, BMI, remission status, disease duration, treatment with TNFi, prior GC treatment, HLA-B27 status, and peripheral arthritis. A $p$ value less than 0.05 was considered significant.

\section{Results \\ Characteristics of patients with nr-axSpA and healthy control subjects}

A total of 107 patients with nr-axSpA and 50 healthy control subjects were recruited for this bone analysis. Six patients with nr-axSpA could not be further analyzed, owing to unacceptable motion artefacts, leaving 101 patients with nr-axSpA to be analyzed. Demographic and disease-specific characteristics are shown in Table 1. Patients with nr-axSpA and control subjects were comparable in age (median [IQR], 45.0 [15.0] vs. 44.76 [26.0] years, $p=0.917$ ), sex (females, $41.6 \%$ vs. $40 \%, p=0.852$ ), and BMI (median [IQR], 26.3 [6.5] vs. 23.8 [5.2], $p=0.118$ ). Of the patients, $37.6 \%$ were former or current smokers, with no significant difference compared with healthy control subjects.

Of patients with nr-axSpA, 75\% showed HLA-B27 positivity, and $12.9 \%$ of the patients had psoriasis, $7.9 \%$ had anterior uveitis, and $6.9 \%$ had IBD in their medical history. Systemic inflammation markers were only minimally elevated, with CRP at $6.2(4.0) \mathrm{mg} / \mathrm{L}$ and ESR at 12.7 (10.5) mm. Median disease duration was 6.5 (9.0) years. Disease activity as assessed by ASDAS-CRP was 2.1 (1.4). Only $14.9 \%$ of patients were in ASDAS-CRP remission, despite $58.4 \%$ of patients being on TNFi treatment with a median (IQR) duration of 2.0 (4.0) years of treatment. Details on the characteristics of patients with nr-axSpA receiving a TNFi and those without a TNFi are summarized in Additional file 1. Clinical assessment by BASMI showed mild impairment of spinal mobility with a median (IQR) score of 1.1 (2) units, whereas patient-reported outcomes revealed a BASDAI of 3.5 (3.6) units and a BASFI of 2.9 (3.8).

Serum 25(OH)vitamin $\mathrm{D}_{3}$ level (median (IQR)) was 32.4 (16.3) $\mathrm{ng} / \mathrm{ml}$. Fractures after inadequate trauma were reported in seven patients (6.9\%), five patients had prior or current antiresorptive treatment, $7.9 \%$ had supplementation with calcium, and $25.7 \%$ had supplementation with 25(OH)vitamin $\mathrm{D}_{3}$.

\section{Bone geometry and vBMD in patients with nr-axSpA}

Bone geometry showed a significant difference in the cortical area between patients with nr-axSpA and control subjects $(p=0.022)$, whereas there was no difference in the total bone area $(p=0.700)$ or the trabecular area $(p=0.374) \quad$ (Table 2). Cortical vBMD suggested a 
Table 1 Demographic and disease-specific characteristics of patients with nonradiographic axial spondyloarthritis and healthy control subjects

\begin{tabular}{|c|c|c|c|}
\hline & $\begin{array}{l}\text { Nr-axSpA } \\
(n=101)\end{array}$ & $\begin{array}{l}\text { Control subjects } \\
(n=50)\end{array}$ & $p$ Value \\
\hline \multicolumn{4}{|l|}{ Demographic characteristics } \\
\hline Female sex, $n(\%)$ & $42(41.6)$ & $20(40)$ & 0.852 \\
\hline Age, yr & $45.0(15.0)$ & $44.76(26.0)$ & 0.917 \\
\hline Height, m & $1.74(0.1)$ & $1.74(0.1)$ & 0.997 \\
\hline Weight, kg & $81.1(21.5)$ & $76.0(18.5)$ & 0.054 \\
\hline Body mass index, $\mathrm{kg} / \mathrm{m}^{2}$ & $26.3(6.5)$ & $23.8(5.2)$ & 0.118 \\
\hline Current or previous smoking, $n(\%)$ & $38(37.6)$ & $11(24.4)$ & 0.119 \\
\hline \multicolumn{4}{|l|}{ Disease-specific characteristics } \\
\hline HLA-B27 positivity, $n$ (\%) & $75(75.0)$ & - & - \\
\hline Duration of disease, yr & $6.5(9.0)$ & - & - \\
\hline Disease remission, $n$ (\%) & $15(14.9)$ & - & - \\
\hline ASDAS-CRP, units & $2.1(1.4)$ & - & - \\
\hline BASDAl, units & $3.5(3.6)$ & - & - \\
\hline C-reactive protein, mg/L & $6.2(4.0)$ & - & - \\
\hline $\mathrm{ESR}, \mathrm{mm}$ & $12.7(10.5)$ & - & - \\
\hline BASFI, units & $2.9(3.8)$ & - & - \\
\hline BASMI, units & $1.1(2)$ & - & - \\
\hline Peripheral arthritis, $n$ (\%) & $35(34.7)$ & - & - \\
\hline Dactylitis, $n(\%)$ & $2(2.0)$ & - & - \\
\hline Enthesitis, $n$ (\%) & $17(16.8)$ & - & - \\
\hline MASES, units & $1.1(1)$ & - & - \\
\hline Psoriasis, n (\%) & $13(12.9)$ & - & - \\
\hline Uveitis, $n$ (\%) & $8(7.9)$ & - & - \\
\hline Inflammatory bowel disease, $n$ (\%) & $7(6.9)$ & - & - \\
\hline Low trauma fracture, $n(\%)$ & $7(6.9)$ & - & - \\
\hline $25(\mathrm{OH})$ vitamin $\mathrm{D}_{3}, \mathrm{ng} / \mathrm{ml}$ & $32.4(16.3)$ & - & - \\
\hline \multicolumn{4}{|l|}{ Treatment modalities } \\
\hline Current biologic therapy ${ }^{\mathrm{a}}, n(\%)$ & $59(58.4)$ & - & - \\
\hline Duration of biologic therapy, yr & $2.0(4.0)$ & & \\
\hline Current DMARD therapy ${ }^{\mathrm{b}}, n(\%)$ & $28(27.7)$ & - & - \\
\hline NSAID, $n(\%)$ & $68(67.3)$ & - & - \\
\hline NSAID daily, $n(\%)$ & $22(21.8)$ & - & - \\
\hline NSAID on demand, $n(\%)$ & $46(45.5)$ & - & - \\
\hline Prednisolone $\geq 5 \mathrm{mg}>3$ months ${ }^{\mathrm{c}}, n(\%)$ & $32(31.7)$ & - & - \\
\hline Calcium substitution, $n(\%)$ & $8(7.9)$ & - & - \\
\hline $25(\mathrm{OH})$ vitamin $\mathrm{D}_{3}$ substitution, $n(\%)$ & $26(25.7)$ & - & - \\
\hline Antiresorptive treatment, $n(\%)$ & $5(5.0)$ & - & - \\
\hline
\end{tabular}

Abbreviations: axSpA Axial spondyloarthritis, ESR Erythrocyte sedimentation rate, 25(OH)vitamin $D_{3} 25$-Hydroxyvitamin $\mathrm{D}_{3}$, ASDAS-CRP Ankylosing Spondylitis Disease Activity Score, defined as inactive $<1.3$, moderate $<2.1$, high $<3.5$, very high $>3.5$ disease activity, disease remission defined as ASDAS-CRP < 1.3, BASDAl Bath Ankylosing Spondylitis Disease Activity Index, BASFI Bath Ankylosing Spondylitis Functional Index, BASMI Bath Ankylosing Spondylitis Metrology Index, MASES Maastrich Ankylosing Spondylitis Enthesitis Score, DMARD Disease-modifying antirheumatic drug, NSAID

Nonsteroidal anti-inflammatory drug

Results are median (IQR) or absolute value and percent

${ }^{\text {a}}$ Tumor necrosis factor inhibitors

${ }^{\mathrm{b}}$ Methotrexate, sulfasalazine, azathioprine, leflunomide, mesalazine

'History of treatment with $\geq 5 \mathrm{mg}$ prednisolone for $\geq 3$ months 
Table 2 Bone microstructure in patients with nonradiographic axial spondyloarthritis assessed by high-resolution peripheral quantitative computed tomography

\begin{tabular}{|c|c|c|c|}
\hline & $\begin{array}{l}\text { axSpA } \\
(n=101)\end{array}$ & $\begin{array}{l}\text { Control subjects } \\
(n=50)\end{array}$ & $p$ Value \\
\hline \multicolumn{4}{|l|}{ Bone geometry } \\
\hline Total bone area, $\mathrm{mm}^{2}$ & $334(108)$ & $326(116)$ & 0.700 \\
\hline Ct. area, $\mathrm{mm}^{2}$ & $60(20)$ & $65(23)$ & 0.022 \\
\hline Tb. area, $\mathrm{mm}^{2}$ & $265(78)$ & $254(83)$ & 0.374 \\
\hline \multicolumn{4}{|c|}{ Volumetric bone mineral density } \\
\hline Total BMD, $\mathrm{HA} / \mathrm{cm}^{3}$ & $313(70)$ & $334(61)$ & 0.042 \\
\hline Ct. BMD, $\mathrm{HA} / \mathrm{cm}^{3}$ & $823(66)$ & $846(78)$ & 0.007 \\
\hline Tb. BMD, $\mathrm{HA} / \mathrm{cm}^{3}$ & $174(44)$ & $183(68)$ & 0.376 \\
\hline Tb. meta $\mathrm{BMD}, \mathrm{HA} / \mathrm{cm}^{3}$ & $234(43)$ & $243(61)$ & 0.310 \\
\hline Tb. inn BMD, $\mathrm{HA} / \mathrm{cm}^{3}$ & $133(47)$ & $141(72)$ & 0.491 \\
\hline \multicolumn{4}{|l|}{ Bone microstructure } \\
\hline $\mathrm{BV} / \mathrm{TV}, \%$ & $14.5(3.7)$ & $15.2(5.7)$ & 0.383 \\
\hline Tb. $\mathrm{N}, \mathrm{mm}^{-1}$ & $2.08(0.31)$ & $2.11(0.42)$ & 0.799 \\
\hline Tb. Th, $\mu \mathrm{m}$ & $70(15)$ & $72(17)$ & 0.486 \\
\hline Tb. Sp, $\mu \mathrm{m}$ & $417(83)$ & $410(104)$ & 0.602 \\
\hline Inhomogeneity, $\mu \mathrm{m}$ & $172(44)$ & $169(47)$ & 0.828 \\
\hline Ct. Th, $\mu \mathrm{m}$ & 767 (190) & $840(160)$ & 0.006 \\
\hline Ct. Po, \% & $2.4(1.66)$ & $2.2(1.57)$ & 0.685 \\
\hline
\end{tabular}

Abbreviations: axSpA Axial spondyloarthritis, Ct. Cortical, $T b$. Trabecular, $T b$. meta BMD Peripheral trabecular density adjacent to cortex, $T b$. inn $B M D$ Central medullary trabecular density, BV/TV Trabecular bone volume, Th Thickness, Sp Separation, Po Porosity

Bone geometry, microstructure, and volumetric bone mineral density (BMD) determined by high-resolution peripheral quantitative computed tomography at the ultradistal radius. Results are median (interquartile range)

Bold indicates significant differences $(p<0.05)$

reduction in patients with axSpA (compared with control subjects; $p=0.007$ ), whereas trabecular BMD showed no difference $(p=0.376)$. Also, no difference between nr-axSpA and control subjects was found for the central medullary and peripheral trabecular density adjacent to cortex $(p=0.310$ and $p=0.941$, respectively). Overall total vBMD was different in patients with axSpA, showing lower values than in control subjects $(p$ $=0.042$ ), which was based on the differences in cortical BMD.

\section{Bone microstructure in patients with nr-axSpA}

Assessment of parameters of bone microstructure showed results very consistent with bone geometry and vBMD with reduced cortical thickness $(p=0.006)$. Trabecular bone structure showed no reduction in trabecular bone volume $(p=0.383)$, number $(p=0.799)$, thickness $(p=0.486)$, or increased inhomogeneity $(p=0.828)$ or trabecular separation $(p=0.602)$. Further cortical analysis showed no increases in cortical porosity $(p=0.685)$ or in pore volume and pore diameter $(p=0.919$ and $p=0.827$, respectively). (Figs. 1 and 2a).

\section{Bone microarchitecture and VBMD with respect to disease duration in patients with $\mathrm{nr}-\mathrm{axSpA}$}

The overall disease duration was 6.5 (9) years, with men having longer disease duration than women (5.0 [10] vs. 2.0 [4], $p=0.021$ ). To assess the impact of disease duration on bone microstructure and vBMD, patients were divided into two groups. Forty-six patients had a disease duration of less than 2 years. Comparison between the two groups and healthy control subjects revealed a significant difference in cortical vBMD $(p=0.012)$, cortical thickness $(p=0.015)$, and cortical pore diameter $(p=0.007)$. No difference in trabecular bone density and microstructure was observed (Table 3). Further intergroup comparisons showed that cortical vBMD is decreased in patients with long-standing disease compared with control subjects $(p=0.004)$, whereas there was only a trend in early SpA $(p=0.096)$. Cortical thickness, however, is already decreased in early nr-axSpA $(p=0.050)$, but the decrease is more prominent in patients with long-standing disease than in control subjects $(p=0.007)$.

\section{Bone microarchitecture and VBMD with respect to glucocorticoid treatment in patients with nr-axSpA}

Patients were divided into two groups according to their prior exposure to GC treatment (>5 $\mathrm{mg}$ of prednisolone equivalent over $\geq 3$ months) in their medical history. $\mathrm{Pa}$ tients treated with GC showed a reduced trabecular vBMD compared with GC-naive patients $(p=0.044)$, whereas there was no difference in total or cortical vBMD. Further, especially vBMD of the centrally located trabecular network $(p=0.014)$ showed a reduction, whereas there was no difference of trabecular bone adjacent to cortex $(p=0.209)$. Bone microstructure showed deterioration of the trabecular network with reduced trabecular bone volume (BV/TV; $p=0.045)$ as well as increased inhomogeneity index $(p=0.007)$ and Tb.Sp $(p=0.037)$ in patients treated with prednisolone. Cortical thickness showed no significant difference ( $p=0.959)$. (Fig. 2b).

\section{Factors associated with cortical bone changes in $\mathrm{nr}-\mathrm{axSpA}$} The first multiple logistic regression model for demographic variables included sex, age, BMI, and smoking status. Male sex was associated with lower cortical $\operatorname{vBMD}(p=0.001)$, whereas female sex was associated with lower trabecular vBMD $(p<0.001)$. The model for total vBMD revealed no demographic predictor (Table 4). In a second model, sex, age, BMI, remission status, disease duration, treatment with TNFi, prior GC treatment, HLA-B27 status, and peripheral arthritis were included. In these models, male sex again was associated with lower cortical vBMD $(p=0.004)$, whereas female sex was 

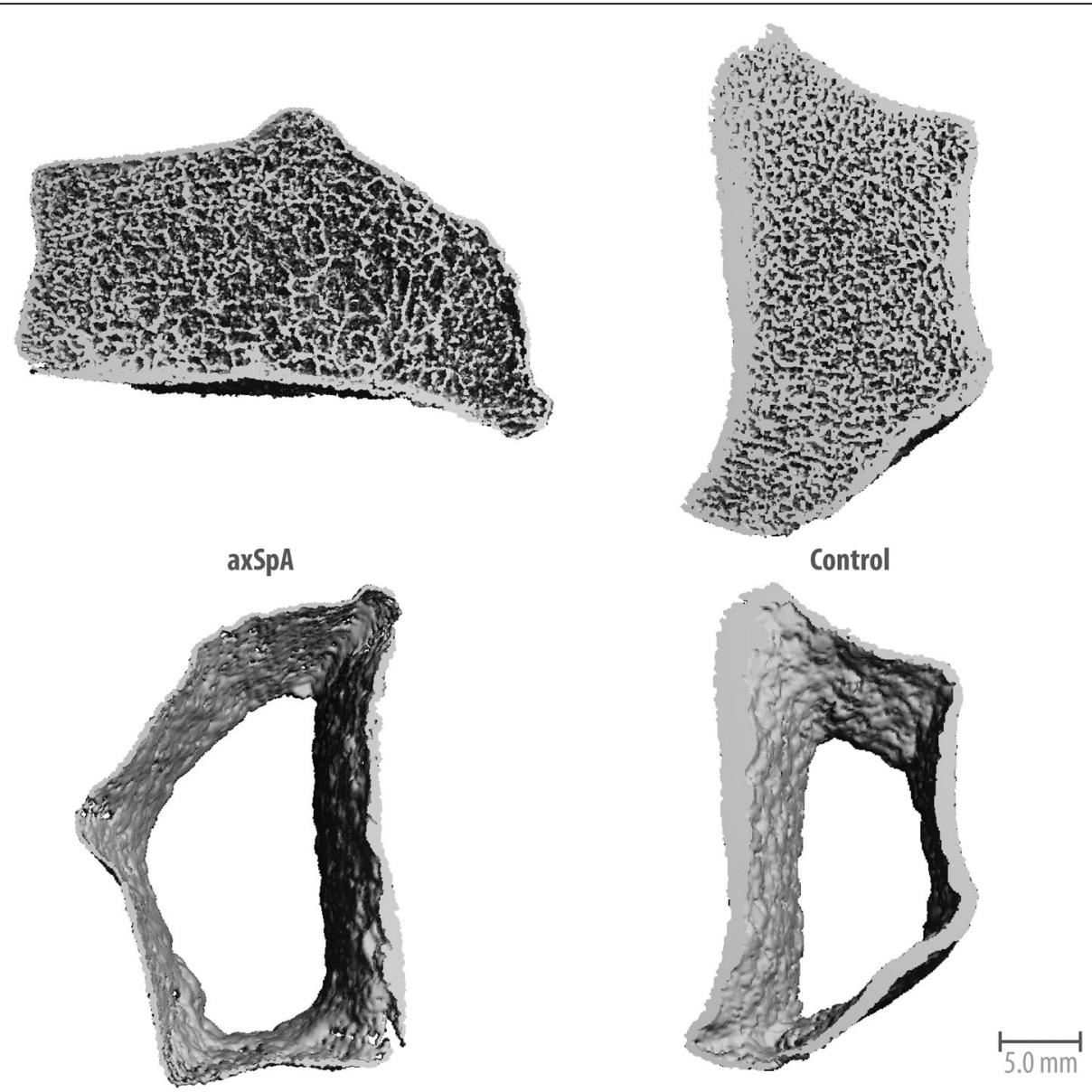

Fig. 1 High-resolution peripheral quantitative computed tomographic scans of the ultradistal radius of patients with axial spondyloarthritis (axSpA) and healthy control subjects. Three-dimensional reconstruction of the cortical bone of the total scan region of patients with axSpA and healthy control subjects displays cortical thinning in patients with spondyloarthritis

associated with lower trabecular vBMD $(p=0.001)$. The model for total vBMD identified no predictors. Prior GC treatment was associated with lower trabecular vBMD $(p=0.041)$. Interestingly, disease duration was positively associated with trabecular vBMD $(p=0.010)$. All further parameters, including age, BMI, remission status, treatment with TNFi, HLA-B27 status, and peripheral arthritis, did not show significant results.

\section{Discussion}

Bone loss is a well-known phenomenon in axSpA, especially in long-standing disease. In the present study, we performed a detailed analysis of bone microstructure in a large cohort of patients with axSpA, with disease duration of less than 2 years in nearly $50 \%$ of patients. Our analysis shows that patients with $\mathrm{nr}-\mathrm{axSpA}$ are characterized by a virtually exclusive cortical but not trabecular bone pathology, which is remarkable. Cortical bone changes characterized by changed geometry, BMD, and microstructure were found early in the disease course of axSpA.

To date, different structural and compartmental changes in bone have been identified using HR-pQCT in systemic inflammatory diseases. Whereas in rheumatoid arthritis a significant deterioration of cortical and trabecular bone has been described, especially in ACPA-positive patients, patients with psoriatic arthritis show predominantly changes of trabecular bone [27, 28]. In contrast, in patients with IBD, primarily a loss of cortical bone has been found [29]. The described changes of cortical bone in $\mathrm{nr}$-axSpA reflect bone structural changes found in patients with IBD.

Our study shows that cortical bone loss as evidenced by cortical thinning happens early in axSpA and can already be found within the first 2 years of disease. In accordance with this, a previous HR-pQCT study of male patients with established AS showed a reduction of cortical vBMD and increased cortical porosity [24]. In this study, however, patients had long-standing disease, with 

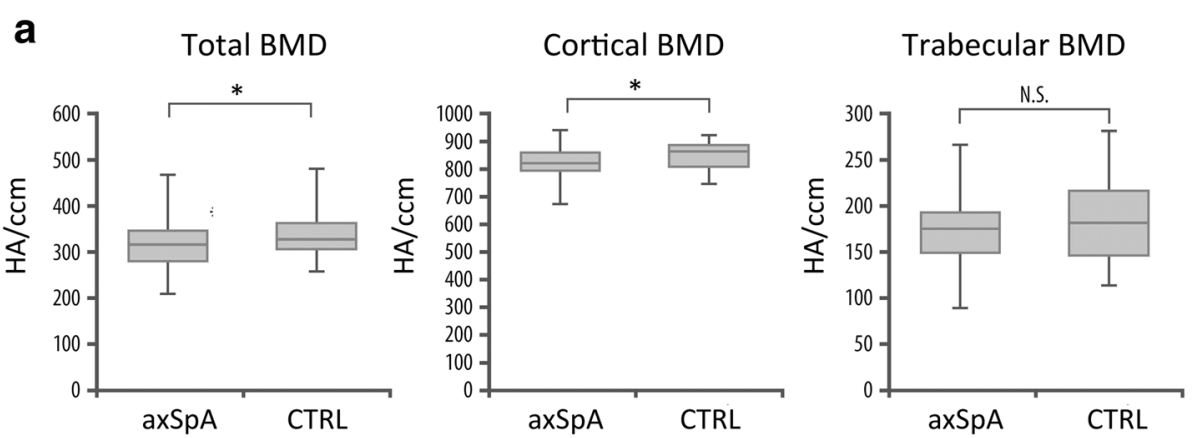

Bone Volume/Tissue Volume

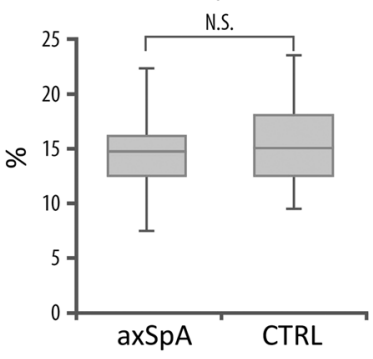

Cortical Thickness

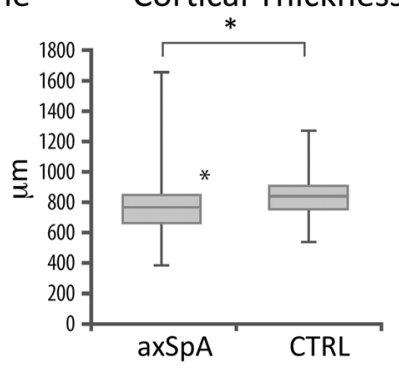

b

Total BMD

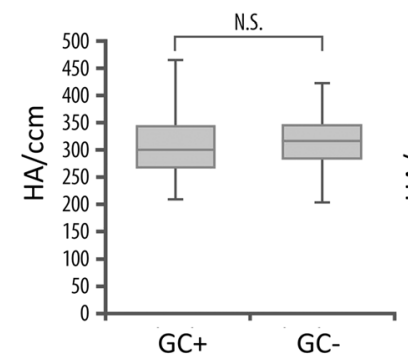

Cortical BMD

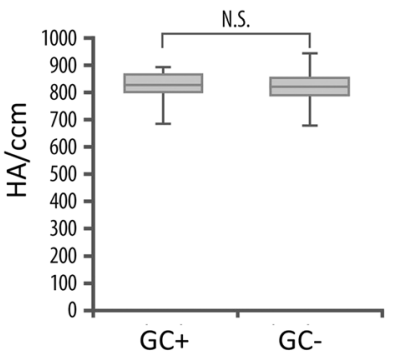

Trabecular BMD

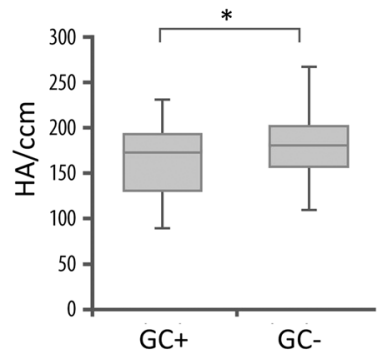

Bone Volume/Tissue Volume

Cortical Thickness
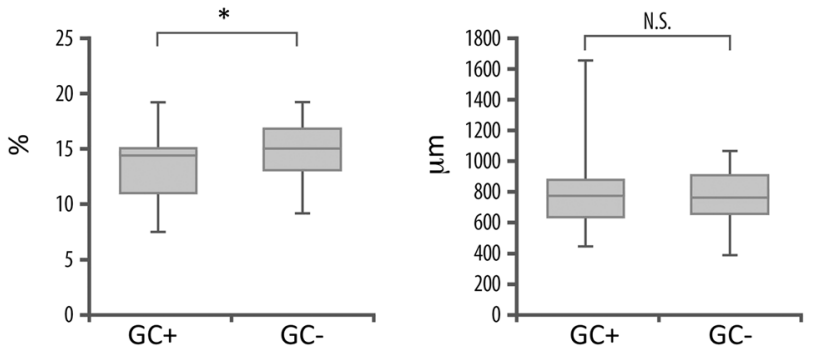

Fig. 2 Differences in bone microarchitecture in patients with nonradiographic axial spondyloarthritis (nr-axSpA). a Changes of total, cortical, and trabecular bone mineral density (BMD) and bone microarchitecture reflected by total bone volume (BV/TV) and cortical thickness (Ct.Th) between patients with axial spondyloarthritis (SpA) and healthy control subjects. b Changes of total, cortical, and trabecular BMD and bone microarchitecture reflected by BV/TV and Ct.Th between patients with nr-axSpA with or without a history of treatment with $>5 \mathrm{mg}$ prednisolone equivalent for more than 3 months. GC Glucocorticoids, N.S. Not significant, HA Hydroxyapatite. ${ }^{*} p<0.05$

a median duration of symptoms longer than 20 years. Cortical thinning and low cross-sectional area in the peripheral skeleton in patients with AS were strongly associated with the presence of vertebral fractures [24]. These findings are in accordance with the previously described association of cortical thinning and loss of cortical BMD at the radius and the tibia with the occurrence of vertebral fractures in men in the general population [30]. The median disease duration in our study was much shorter ( 6.5 years) than in the aforementioned 
Table 3 Bone microstructure in patients with nonradiographic axial spondyloarthritis with short and longer disease duration and in healthy control subjects

\begin{tabular}{|c|c|c|c|c|c|c|c|}
\hline & $\begin{array}{l}\text { axSpA } \\
<2 \mathrm{yr} \\
(n= \\
46)\end{array}$ & $\begin{array}{l}\text { axSpA } \\
>2 \mathrm{yr} \\
(n=55)\end{array}$ & $\begin{array}{l}\text { Control } \\
\text { subjects } \\
(n=50)\end{array}$ & $\begin{array}{l}\text { axSpA }<2 \text { yr vs. } \\
\text { axSpA } \\
>2 \text { years vs. control } \\
\text { subjects }\end{array}$ & $\begin{array}{l}\text { axSpA }<2 \text { yr vs. control } \\
\text { subjects }\end{array}$ & $\begin{array}{l}\text { axSpA }<2 \text { yr vs. } \\
\text { axSpA }>2 \text { yr }\end{array}$ & $\begin{array}{l}\text { axSpA > } 2 \text { yr vs. control } \\
\text { subjects }\end{array}$ \\
\hline \multicolumn{8}{|l|}{ Bone geometry } \\
\hline $\begin{array}{l}\text { Total bone area, } \\
\mathrm{mm}^{2}\end{array}$ & $\begin{array}{l}317 \\
(114)\end{array}$ & $\begin{array}{l}349 \\
(94)\end{array}$ & $326(116)$ & 0.060 & 0.322 & 0.023 & 0.136 \\
\hline Ct. area, $\mathrm{mm}^{2}$ & $59(18)$ & $61(22)$ & $65(23)$ & 0.068 & 0.032 & 0.703 & 0.066 \\
\hline Tb. area, $\mathrm{mm}^{2}$ & $\begin{array}{l}250 \\
(95)\end{array}$ & $\begin{array}{l}277 \\
(88)\end{array}$ & $254(83)$ & 0.068 & 0.628 & 0.041 & 0.062 \\
\hline \multicolumn{8}{|c|}{ Volumetric bone mineral density } \\
\hline $\begin{array}{l}\text { Total BMD, HA/ } \\
\mathrm{cm}^{3}\end{array}$ & $\begin{array}{l}317 \\
(49)\end{array}$ & $\begin{array}{l}309 \\
(75)\end{array}$ & $334(61)$ & 0.096 & 0.170 & 0.423 & 0.036 \\
\hline $\begin{array}{l}\text { Ct. BMD, HA/ } \\
\mathrm{cm}^{3}\end{array}$ & $\begin{array}{l}833 \\
(62)\end{array}$ & $\begin{array}{l}814 \\
(65)\end{array}$ & $846(78)$ & 0.012 & 0.096 & 0.167 & 0.004 \\
\hline $\begin{array}{l}\text { Tb. BMD, HA/ } \\
\mathrm{cm}^{3}\end{array}$ & $\begin{array}{l}173 \\
(44)\end{array}$ & $\begin{array}{l}175 \\
(47)\end{array}$ & $183(68)$ & 0.571 & 0.289 & 0.564 & 0.610 \\
\hline $\begin{array}{l}\text { Tb. meta BMD, } \\
\mathrm{HA} / \mathrm{cm}^{3}\end{array}$ & $\begin{array}{l}233 \\
(38)\end{array}$ & $\begin{array}{l}234 \\
(51)\end{array}$ & $243(61)$ & 0.561 & 0.294 & 0.728 & 0.465 \\
\hline $\begin{array}{l}\text { Tb. inn BMD, } \\
\mathrm{HA} / \mathrm{cm}^{3}\end{array}$ & $\begin{array}{l}132 \\
(47)\end{array}$ & $\begin{array}{l}135 \\
(52)\end{array}$ & $141(72)$ & 0.618 & 0.359 & 0.464 & 0.753 \\
\hline \multicolumn{8}{|l|}{ Bone microstructure } \\
\hline $\mathrm{BV} / \mathrm{TV}, \%$ & $\begin{array}{l}14.4 \\
(3.7)\end{array}$ & $\begin{array}{l}14.6 \\
(3.9)\end{array}$ & $15.2(5.7)$ & 0.575 & 0.288 & 0.564 & 0.628 \\
\hline Tb. $\mathrm{N}, \mathrm{mm}^{-1}$ & $\begin{array}{l}2.12 \\
(0.30)\end{array}$ & $\begin{array}{l}2.05 \\
(0.41)\end{array}$ & $2.11(0.42)$ & 0.534 & 0.739 & 0.263 & 0.480 \\
\hline Tb. Th, $\mu \mathrm{m}$ & $68(15)$ & $71(15)$ & $72(17)$ & 0.244 & 0.171 & 0.120 & 0.946 \\
\hline Tb. Sp, $\mu \mathrm{m}$ & $\begin{array}{l}410 \\
(66)\end{array}$ & $\begin{array}{l}423 \\
(107)\end{array}$ & $410(104)$ & 0.677 & 0.956 & 0.480 & 0.424 \\
\hline $\begin{array}{l}\text { Inhomogeneity, } \\
\mu \mathrm{m}\end{array}$ & $\begin{array}{l}165 \\
(41)\end{array}$ & $\begin{array}{l}178 \\
(48)\end{array}$ & 169 (47) & 0.351 & 0.575 & 0.149 & 0.399 \\
\hline Ct. Th, $\mu \mathrm{m}$ & $\begin{array}{l}775 \\
(160)\end{array}$ & $\begin{array}{l}759 \\
(235)\end{array}$ & $840(160)$ & 0.015 & 0.050 & 0.245 & 0.007 \\
\hline Ct. Po, \% & $\begin{array}{l}2.0 \\
(1.46)\end{array}$ & $\begin{array}{l}2.8 \\
(1.72)\end{array}$ & $2.2(1.57)$ & 0.064 & 0.373 & 0.020 & 0.157 \\
\hline
\end{tabular}

Abbreviations: BMD Bone mineral density, SpA Spondyloarthritis, Ct. Cortical, Tb. Trabecular, Tb. meta Bone mineral density peripheral trabecular density adjacent to cortex, Tb. inn Bone mineral density central medullary trabecular density, BV/TV Trabecular bone volume, Th Thickness, Sp Separation, Po Porosity Bone geometry, microstructure, and volumetric BMD by high-resolution peripheral quantitative computed tomography at the ultradistal radius. Results are median (IQR)

Bold indicates significant differences $(p<0.05)$

study. Nonetheless, about half of the patients with $n r$-axSpA did not have early disease $(<2$ years) anymore and were treated with TNFi. The fact that some patients had a disease duration longer than 2 years may also explain the observation that $7 \%$ of the patients with axSPA already had a history of low traumatic fracture. Overall, however, our data show systemic deterioration of cortical bone microstructure even at an early stage of disease in patients with nr-axSpA.

Data are so far limited regarding the factors that influence bone microarchitecture in patients with $\mathrm{nr}$-axSpA and patients with AS. Multiple logistic regression identified male sex to be associated with lower cortical vBMD.
Interestingly, loss of cortical vBMD was independent of standard disease-related features such as age, BMI, remission status, anti-TNF treatment, HLA-B27 status, and peripheral arthritis. In contrast to cortical vBMD, trabecular vBMD was lower in women than in men. These findings are in accordance with previous population-based studies showing higher trabecular vBMD in men, whereas cortical vBMD is higher in women [31]. Disease duration was associated positively with higher trabecular vBMD in the present study, which can be explained by longer disease duration in men than in women. These results confirm previous findings of Haroon et al,, who investigated sex 
Table 4 Predictors of reduced total, cortical, and trabecular bone mineral density in patients with nonradiographic axial spondyloarthritis

\begin{tabular}{|c|c|c|c|c|c|c|c|c|c|}
\hline & \multicolumn{3}{|c|}{ Total BMD } & \multicolumn{3}{|c|}{ Ct. BMD } & \multicolumn{3}{|c|}{ Trab. BMD } \\
\hline & $\bar{\beta}$ & $T$ & $p$ & $\bar{\beta}$ & $T$ & $p$ & $\bar{\beta}$ & $T$ & $p$ \\
\hline \multicolumn{10}{|l|}{ Model 1} \\
\hline Age & 0.006 & 0.068 & 0.946 & -0.038 & -0.449 & 0.654 & -0.073 & -0.952 & 0.342 \\
\hline Sex (male vs. female) & -0.143 & -1.730 & 0.086 & 0.285 & 3.523 & 0.001 & -0.466 & -6.324 & $<0.001$ \\
\hline BMl & 0.079 & 0.915 & 0.362 & -0.004 & -0.042 & 0.966 & 0.083 & 1.080 & 0.282 \\
\hline Smoking (yes/no) & 0.118 & 1.415 & 0.159 & -0.041 & -0.505 & 0.615 & 0.103 & 1.378 & 0.171 \\
\hline Intercept & - & 11.570 & $<0.001$ & - & 29.784 & $<0.001$ & - & 12.765 & $<0.001$ \\
\hline$R^{2}$ adjusted & - & 0.016 & - & - & 0.059 & - & - & 0.219 & - \\
\hline \multicolumn{10}{|l|}{ Model 2} \\
\hline Age & -0.109 & -0.913 & 0.364 & -0.094 & -0.858 & 0.393 & -0.151 & -1.498 & 0.138 \\
\hline Sex & -0.095 & -0.847 & 0.399 & 0.300 & 2.937 & 0.004 & -0.420 & -4.448 & $<0.001$ \\
\hline BMI & 0.115 & 1.036 & 0.303 & 0.017 & 0.164 & 0.870 & 0.159 & 1.689 & 0.095 \\
\hline Remission & -0.017 & -0.150 & 0.881 & 0.015 & 0.147 & 0.883 & 0.048 & 0.512 & 0.610 \\
\hline Disease duration & 0.157 & 1.241 & 0.218 & -0.169 & -1.460 & 0.148 & 0.280 & 2.625 & 0.010 \\
\hline Anti-TNF & -0.094 & -0.776 & 0.440 & -0.131 & -1.176 & 0.243 & -0.160 & -1.557 & 0.123 \\
\hline GC (yes/no) & -0.132 & -1.131 & 0.261 & 0.109 & 1.023 & 0.309 & -0.205 & -2.078 & 0.041 \\
\hline HLA-B27 positivity & -0.027 & -0.254 & 0.800 & 0.002 & 0.020 & 0.984 & 0.027 & 0.304 & 0.762 \\
\hline Peripheral arthritis & 0.011 & 0.095 & 0.924 & -0.041 & -0.404 & 0.687 & -0.093 & -0.987 & 0.327 \\
\hline Intercept & - & 8.522 & $<0.001$ & - & 23.225 & $<0.001$ & - & 9.761 & $<0.001$ \\
\hline$R^{2}$ adjusted & - & -0.038 & - & - & 0.130 & - & - & 0.258 & - \\
\hline
\end{tabular}

Abbreviations: BMD Bone mineral density, Ct. BMD Cortical bone mineral density, Trab. BMD Trabecular bone mineral density, axSpA axial spondyloarthritis, BMI Body mass index, Anti-TNF Current treatment with anti-tumor necrosis factor a inhibitor, GC History of glucocorticoid treatment with $\geq 5$ mg prednisolone equivalent daily for $>3$ mo

Remission status according to Ankylosing Spondylitis Disease Activity Score (ASDAS-CRP, inactive disease ASDAS-CRP < 1.3)

Bold indicates significant differences $(p<0.05)$

differences among patients with AS and showed decreased cortical vBMD in men, whereas trabecular vBMD was worse in women [23].

Although nr-axSpA specifically affects cortical bone, an evaluation of those patients treated with GCs $>5 \mathrm{mg}$ daily for $>3$ months in the past showed specific loss of trabecular bone associated with reduction of trabecular vBMD, lower total bone volume, and higher trabecular separation and inhomogeneity. Sutter et al. investigated postmenopausal women treated with oral GCs for $>3$ months and age-/race-matched control subjects using HR-pQCT and DXA. In their study, despite no difference in areal BMD, GC-treated women showed an impairment of cortical and trabecular vBMD and bone microarchitecture [32]. Moreover, later stages of the disease, particularly in patients with severe AS with syndesmophyte formation, also trabecular vBMD appears to decrease, which is reflected by a study from Devogelaer and colleagues [9].

The strength of the present study is a detailed assessment of bone macro- and microarchitecture using HR-pQCT in patients with axSpA. To date, this is the largest nr-axSpA cohort with detailed bone analysis by HR-pQCT. A further strength and novelty of this work is the assessment of patients with short disease duration. A limitation is, of course, that HR-pQCT cannot analyze the spine but is confined to peripheral sites. However, several studies have previously shown that structural changes in the peripheral bones reflect bone changes as well as fracture risk in the axial skeleton [22, 23].

The reason why nr-axSpA virtually exclusively affects cortical bone is not entirely clear. It can be speculated that such changes reflect increased cortical bone remodeling. For instance, it has long been known that the remodeling of cortical bone is highly dependent on strain [33], and later concepts even suggested that cortical bone remodeling may even be entirely dependent on microcracks [34]. Hence, altered bone responses to mechanical forces in nr-axSpA may be triggers for increased cortical bone remodeling and bone loss. In accordance with this, prostaglandin $E_{2}$, a prototype inflammatory mediator released upon injury and having a central role in nr-axSpA, has been shown to enhance cortical bone remodeling [35]. The disbalance in cortical bone in patients with nr-axSpA, however, may stem from cytokines such as interleukin-17, which effectively suppress bone formation but at the same time increase bone resorption [36, 37]. 


\section{Conclusions}

In this study, we show that axSpA specifically leads to an early and virtually exclusive loss of cortical bone, thereby contrasting with many other inflammatory diseases but resembling features of bone loss observed in patients with IBD. In contrast, trabecular bone does not appear to be directly influenced by axSpA.

\section{Additional file}

Additional file 1: Table S1 Demographic parameters, disease-specific characteristics, and bone microstructure in patients with nonradiographic axial spondyloarthritis (nr-axSpA) with or without TNFi treatment. (DOCX 16 kb)

\section{Abbreviations \\ ACPA: Anticitrullinated protein antibodies; AS: Ankylosing spondylitis; ASAS: Assessment of Spondyloarthritis international Society; ASDAS: Ankylosing Spondylitis Disease Activity Score; BASDAl: Bath Ankylosing Spondylitis Disease Activity Index; BASMI: Bath Ankylosing Spondylitis Metrology Index; BMD: Bone mineral density; BMI: Body mass index; BV/TV: Bone volume per tissue volume; CRP: C-reactive protein Ct: Cortical bone; Ct.Po: Cortical porosity; Ct.Th: Cortical thickness: DMARD: Disease-modifying antirheumatic drug; DXA: Dual-energy x-ray ab- sorptiometry; ESR: Erythrocyte sedimentation rate; GC: Glucocorticoid; HA: Hydroxyapatite; HLA-B27: Human leukocyte antigen B27; HR-pQCT: High- resolution quantitative computed tomography; IBD: Inflammatory bowel disease; MASES: Maastricht Ankylosing Spondylitis Enthesitis Score; SpA: Spondyloarthritis; Tb: Trabecular bone; Tb.Sp: Trabecular separation; TNF: Tumor necrosis factor a; TNFi: Inhibition of tumor necrosis factor $a_{\text {; }}$ $\checkmark B M D$ : Volumetric bone mineral density}

\section{Acknowledgements}

This study was supported by the Bundesministerium fuer Bildung und Forschung (BMBF project METARTHROS), the Deutsche Forschungsgemeinschaft (CRC1181), the Marie Curie project Osteoimmune and the Innovative Medicines Initiative-funded project Be The Cure (BTCure). CPF was supported by Cienciassem Fronteiras from Conselho Nacional de Desenvolvimento Cientifico e Tecnologico (CNPq), Brazil.

\section{Funding}

This study was supported by the Deutsche Forschungsgemeinschaft (CRC1181), the Bundesministerium für Bildung und Forschung (BMBF; project METARTHROS) and the Innovative Medicine Initiative-funded project Rheuma Tolerance for Cure (RTCure).

\section{Availability of data and materials}

All data generated or analyzed during this study are included in this published article.

\section{Authors' contributions}

AN, JH, and AK collected and analyzed the data. LS performed the scan evaluation and motion grading. $\mathrm{JH}$ and $\mathrm{ME}$ performed the statistical analysis. $A B$ provided data of healthy control subjects. AN, JH, AK, ME, CPF, DS, CM, $R K, H R$, JR, and GS interpreted the data and revised the manuscript. AN, JH, and GS wrote the manuscript. The present work was performed in fulfillment of the requirements for obtaining the 'Dr. med.' degree by AN. All authors read and approved the final manuscript.

\section{Ethics approval and consent to participate}

Ethical approval was obtained from the institutional review board of the Universitatsklinikum Erlangen. Patients provided written informed consent.

\section{Competing interests}

The authors declare that they have no competing interests.

\section{Publisher's Note}

Springer Nature remains neutral with regard to jurisdictional claims in published maps and institutional affiliations.

\section{Author details}

'Department of Internal Medicine 3, Friedrich Alexander University Erlangen-Nurnberg and Universitätsklinikum Erlangen, Ulmenweg 18, 91054 Erlangen, Germany. ${ }^{2}$ St. Vincent Hospital, VINFORCE Study Group, Medical University of Vienna, Vienna, Austria. ${ }^{3}$ Division of Rheumatology, Faculdade de Medicina da Universidade de São Paulo, São Paulo, Brazil.

Received: 9 February 2018 Accepted: 9 May 2018

Published online: 30 August 2018

\section{References}

1. Donnelly S, Doyle DV, Denton A, Rolfe I, McCloskey EV, Spector TD. Bone mineral density and vertebral compression fracture rates in ankylosing spondylitis. Ann Rheum Dis. 1994;53:117-21.

2. Kilic $\mathrm{E}$, Ozgocmen S. Bone mass in axial spondyloarthritis: a literature review. World J Orthop. 2015:6:298-310.

3. Klingberg E, Lorentzon M, Mellstrom D, Geijer M, Gothlin J, Hilme E, et al. Osteoporosis in ankylosing spondylitis - prevalence, risk factors and methods of assessment. Arthritis Res Ther. 2012;14:R108.

4. Lange U, Kluge A, Strunk J, Teichmann J, Bachmann G. Ankylosing spondylitis and bone mineral density — what is the ideal tool for measurement? Rheumatol Int. 2005;26:115-20.

5. Speden DJ, Calin Al, Ring FJ, Bhalla AK. Bone mineral density, calcaneal ultrasound, and bone turnover markers in women with ankylosing spondylitis. J Rheumatol. 2002;29:516-21.

6. Karberg K, Zochling J, Sieper J, Felsenberg D, Braun J. Bone loss is detected more frequently in patients with ankylosing spondylitis with syndesmophytes. J Rheumatol. 2005;32:1290-8.

7. Meirelles ES, Borelli A, Camargo OP. Influence of disease activity and chronicity on ankylosing spondylitis bone mass loss. Clin Rheumatol. 1999; 18:364-8.

8. Singh A, Bronson W, Walker SE, Allen SH. Relative value of femoral and lumbar bone mineral density assessments in patients with ankylosing spondylitis. South Med J. 1995;88:939-43.

9. Devogelaer JP, Maldague B, Malghem J, Nagant de Deuxchaisnes C. Appendicular and vertebral bone mass in ankylosing spondylitis: a comparison of plain radiographs with single- and dual-photon absorptiometry and with quantitative computed tomography. Arthritis Rheum. 1992;35:1062-7.

10. Schett G, David JP. The multiple faces of autoimmune-mediated bone loss. Nat Rev Endocrinol. 2010;6:698-706

11. Akgol G, Kamanli A, Ozgocmen S. Evidence for inflammation-induced bone loss in non-radiographic axial spondyloarthritis. Rheumatology (Oxford). 2014:53:497-501.

12. Briot K, Durnez A, Paternotte S, Miceli-Richard C, Dougados M, Roux C. Bone oedema on MRI is highly associated with low bone mineral density in patients with early inflammatory back pain: results from the DESIR cohort. Ann Rheum Dis. 2013;72:1914-9.

13. Allali F, Breban M, Porcher R, Maillefert JF, Dougados M, Roux C. Increase in bone mineral density of patients with spondyloarthropathy treated with anti-tumour necrosis factor a. Ann Rheum Dis. 2003:62:347-9.

14. Arends S, Spoorenberg A, Houtman PM, Leijsma MK, Bos R, Kallenberg CG, et al. The effect of three years of TNFa blocking therapy on markers of bone turnover and their predictive value for treatment discontinuation in patients with ankylosing spondylitis: a prospective longitudinal observational cohort study. Arthritis Res Ther. 2012;14:R98.

15. Kang KY, Ju JH, Park SH, Kim HY. The paradoxical effects of TNF inhibitors on bone mineral density and radiographic progression in patients with ankylosing spondylitis. Rheumatology (Oxford). 2013;52:718-26.

16. Klingberg E, Geijer M, Gothlin J, Mellstrom D, Lorentzon M, Hilme E, Hedberg M, Carlsten H, Forsblad-D'Elia H. Vertebral fractures in ankylosing spondylitis are associated with lower bone mineral density in both central and peripheral skeleton. J Rheumatol. 2012;39:1987-95.

17. Seeman E, Delmas PD. Bone quality - the material and structural basis of bone strength and fragility. N Engl J Med. 2006;354:2250-61.

18. Stein EM, Kepley A, Walker M, Nickolas TL, Nishiyama K, Zhou B, et al. Skeletal structure in postmenopausal women with osteopenia and fractures 
is characterized by abnormal trabecular plates and cortical thinning. J Bone Miner Res. 2014;29:1101-9.

19. Boutroy S, Bouxsein ML, Munoz F, Delmas PD. In vivo assessment of trabecular bone microarchitecture by high-resolution peripheral quantitative computed tomography. J Clin Endocrinol Metab. 2005;90:6508-15.

20. Cheung AM, Adachi JD, Hanley DA, Kendler DL, Davison KS, Josse R, et al. High-resolution peripheral quantitative computed tomography for the assessment of bone strength and structure: a review by the Canadian Bone Strength Working Group. Curr Osteoporos Rep. 2013;11:136-46.

21. Amstrup AK, Jakobsen NF, Moser E, Sikjaer T, Mosekilde L, Rejnmark L. Association between bone indices assessed by DXA, HR-pQCT and QCT scans in post-menopausal women. J Bone Miner Metab. 2016;34:638-45.

22. Engelke K, Libanati C, Fuerst T, Zysset P, Genant HK. Advanced CT based in vivo methods for the assessment of bone density, structure, and strength. Curr Osteoporos Rep. 2013:11:246-55.

23. Haroon N, Szabo E, Raboud JM, McDonald-Blumer H, Fung L, Josse RG, et al. Alterations of bone mineral density, bone microarchitecture and strength in patients with ankylosing spondylitis: a cross-sectional study using highresolution peripheral quantitative computerized tomography and finite element analysis. Arthritis Res Ther. 2015;17:377.

24. Klingberg E, Lorentzon M, Gothlin J, Mellstrom D, Geijer M, Ohlsson C, et al. Bone microarchitecture in ankylosing spondylitis and the association with bone mineral density, fractures, and syndesmophytes. Arthritis Res Ther. 2013;15:R179.

25. Simon D, Kleyer A, Stemmler F, Simon C, Berlin A, et al. Age- and sexdependent changes of intra-articular cortical and trabecular bone structure and the effects of rheumatoid arthritis. J Bone Miner Res. 2017;32:722-30.

26. de Waard EAC, Sarodnik C, Pennings A, de Jong JJA, Savelberg HHCM, van Geel TA, et al. The reliability of HR-pQCT derived cortical bone structural parameters when using uncorrected instead of corrected automatically generated endocortical contours in a cross-sectional study: the Maastricht study. Calcif Tissue Int. 2018; https://doi.org/10.1007/s00223-018-0416-2.

27. Kocijan R, Finzel S, Englbrecht M, Engelke K, Rech J, Schett G. Differences in bone structure between rheumatoid arthritis and psoriatic arthritis patients relative to autoantibody positivity. Ann Rheum Dis. 2014:73:2022-8.

28. Kocijan R, Englbrecht M, Haschka J, Simon D, Kleyer A, Finzel S, et al. Quantitative and qualitative changes of bone in psoriasis and psoriatic arthritis patients. J Bone Miner Res. 2015;30:1775-83.

29. Haschka J, Hirschmann S, Kleyer A, Englbrecht M, Faustini F, Simon D, et al. High-resolution quantitative computed tomography demonstrates structural defects in cortical and trabecular bone in IBD patients. J Crohns Colitis. 2016;10:532-40

30. Szulc P, Boutroy S, Vilayphiou N, Chaitou A, Delmas PD, Chapurlat R. Crosssectional analysis of the association between fragility fractures and bone microarchitecture in older men: the STRAMBO study. J Bone Miner Res. 2011:26:1358-67.

31. Khosla S, Riggs BL, Atkinson EJ, Oberg AL, McDaniel LJ, Holets M, et al. Effects of sex and age on bone microstructure at the ultradistal radius: a population-based noninvasive in vivo assessment. J Bone Miner Res. 2006; 21:124-31.

32. Sutter S, Nishiyama KK, Kepley A, Zhou B, Wang J, McMahon DJ, et al. Abnormalities in cortical bone, trabecular plates, and stiffness in postmenopausal women treated with glucocorticoids. J Clin Endocrinol Metab. 2014;99:4231-40.

33. Carter DR. Mechanical loading histories and cortical bone remodeling. Calcif Tissue Int. 1984;36:S19-24.

34. Martin RB. Is all cortical bone remodeling initiated by microdamage? Bone. 2002;30:8-13.

35. Jee WS, Mori S, Li XJ, Chan S. Prostaglandin $E_{2}$ enhances cortical bone mass and activates intracortical bone remodeling in intact and ovariectomized female rats. Bone. 1990;11:253-66.

36. Uluckan O, Jimenez M, Karbach S, Jeschke A, Graña O, Keller J, et al. Chronic skin inflammation leads to bone loss by IL-17-mediated inhibition of Wnt signaling in osteoblasts. Sci Transl Med. 2016;8:330ra337.

37. Kotake S, Udagawa N, Takahashi N, Matsuzaki K, Itoh K, Ishiyama S, et al. IL17 in synovial fluids from patients with rheumatoid arthritis is a potent stimulator of osteoclastogenesis. J Clin Invest. 1999;103:1345-52.

\section{Ready to submit your research? Choose BMC and benefit from:}

- fast, convenient online submission

- thorough peer review by experienced researchers in your field

- rapid publication on acceptance

- support for research data, including large and complex data types

- gold Open Access which fosters wider collaboration and increased citations

- maximum visibility for your research: over $100 \mathrm{M}$ website views per year

At BMC, research is always in progress.

Learn more biomedcentral.com/submissions 